\title{
L-Buthionine Sulfoximine Detection and Quantification in Polyurea Dendrimer Nanoformulations
}

\author{
Pedro Mota ${ }^{1} \mathbb{D}$, Rita F. Pires ${ }^{1}$, Jacinta Serpa ${ }^{2,3}$ and Vasco D. B. Bonifácio ${ }^{1, * \mathbb{C}}$ \\ 1 CQFM-IN and IBB - Institute for Bioengineering and Biosciences, Instituto Superior Técnico, \\ Universidade de Lisboa, 1049-001 Lisboa, Portugal \\ 2 CEDOC, Chronic Diseases Research Centre, NOVA Medical School, Faculdade de Ciências Médicas, \\ Universidade NOVA de Lisboa, Campo dos Mártires da Pátria 130, 1169-056 Lisboa, Portugal \\ 3 Instituto Português de Oncologia de Lisboa Francisco Gentil (IPOLFG), Rua Prof. Lima Basto, \\ 1099-023 Lisboa, Portugal \\ * Correspondence: vasco.bonifacio@tecnico.ulisboa.pt; Tel.: +351-218-419-218
}

Received: 13 August 2019; Accepted: 20 August 2019; Published: 27 August 2019

check for updates

\begin{abstract}
L-Buthionine sulfoximine (L-BSO) is an adjuvant drug that is reported to increase the sensitivity of cancer cells to neoplastic agents. Dendrimers are exceptional drug delivery systems and L-BSO nanoformulations are envisaged as potential chemotherapeutics. The absorption of L-BSO at a low wavelength limits its detection by conventional analytical tools. A simple and sensitive method for L-BSO detection and quantification is now reported. In this study, L-BSO was encapsulated in a folate-targeted generation four polyurea dendrimer (PURE $\left.\mathrm{G}_{4}-\mathrm{FA}_{2}\right)$ and its release profile was followed for $24 \mathrm{~h}$ at $\mathrm{pH} 7.4$ and $37^{\circ} \mathrm{C}$. The protocol uses in situ L-BSO derivatization, by the formation of a catechol-derived orto-quinone, followed by visible detection of the derivative at $503 \mathrm{~nm}$. The structure of the studied L-BSO derivative was assessed by NMR spectroscopy.
\end{abstract}

Keywords: buthionine sulfoximine; polyurea dendrimers; catechol; nanoformulation; UV-Vis detection; derivatization

\section{Introduction}

The detection of organic molecules that absorb at low wavelengths is a critical issue and a challenge for analytical chemistry. Ultraviolet radiation having wavelengths less than $200 \mathrm{~nm}$ is difficult to handle and is rarely used as a routine tool for structural analysis. To overcome this problem, chemical derivatization is often employed in order to conduct indirect spectrophotometric analysis. Therefore, depending on the reactivity and available functional groups of the analytes, we can choose from a variety of chemical or enzymatic reactions in order to bring absorption to longer wavelengths [1].

Buthionine sulfoximine (BSO) is a specific $\gamma$-glutamylcysteine synthetase $(\gamma$-GCS) inhibitor that blocks a rate-limiting step in glutathione (GSH) biosynthesis by inhibiting the synthesis of glutamylcysteine, the first precursor of GSH [2]. BSO is a chiral molecule and its racemate was first successfully synthesized in 1979 [3]. The two isomers (D and L) were also prepared and investigated (Figure 1), however L-buthionine-( $S, R)$-sulfoximine, contrary to the racemate and the $\mathrm{D}$ isomer, shows a high inhibition efficacy [4]. More recently, a new improved synthetic route of the racemate, using mild and safe conditions, was also reported [5]. 
<smiles>CCCCS(=N)(=O)CC[C@H](N)C(=O)O</smiles>

L-Buthionine- $(S, R)$-sulfoximine<smiles>CCCCS(=N)(=O)CC[C@H](N)C(=O)O</smiles>

D-Buthionine- $(S, R)$-sulfoximine

Figure 1. Chemical structure of buthionine sulfoximine isomers.

The fact that BSO is capable of altering metabolism makes it a promising key molecule for cancer therapeutics, and its role in cell growth inhibition, apoptosis induction [6], drug resistance reduction [7], and as a cancer adjuvant therapeutic in ovarian clear cell carcinoma [8], and others [9] has already been investigated.

Nevertheless, BSO detection and quantification in biological assays is still limited, mainly due to its very low molar absorptivity and an absorption maximum below $200 \mathrm{~nm}$ [10]. Therefore, its detection is difficult using high-performance liquid chromatography (HPLC) using a UV detector. BSO detection, along with isomers separation, was first reported in 1987 using HPLC after sample derivatization with $o$-phthalaldehyde [11]. However, this method has several limitations. Because of the instability of the $o$-phthalaldehyde derivative at room temperature, each sample was prepared immediately prior to injection onto the HPLC column. Additionally, butyrophenone, used as the internal standard, required a fluorescence detector in addition to the UV detector. Another limitation of this method was the prolonged time of the analysis (>75 min/sample). Later, in 1993, an alternative method was developed. In this case, derivatization was performed using phenylisothiocyanate, which produces a more stable derivative [12], but its high toxicity is a major drawback.

In this work, we developed a simple, safe, and fast methodology for visible detection of L-Buthionine sulfoximine (L-BSO) using a folate-targeted polyurea dendrimer nanoformulation.

\section{Results and Discussion}

\subsection{L-BSO Encapsulation and Release Studies}

Aiming at future in vivo studies, the L-BSO release was performed at $37^{\circ} \mathrm{C}$ under physiological conditions ( $\mathrm{pH}$ 7.4). However, due to the stability of the reagents and derivatives at lower $\mathrm{pHs,}$ the method is also applicable in studies involving tumor cells or tissues under acidic environments [13]. PURE dendrimers were chosen as a model drug delivery system due to their reported biocompatibility and biodegradability [14]. It is well known that PURE dendrimers in aqueous solutions have the ability to produce positively charged species [15] as a result of amines protonation. This feature leads to a structure expansion as a result of charge repulsions between the dendrimer branches, thus speeding cargo release. A polyurea generation four dendrimer, targeted with folate (PURE $\left.\mathrm{G}_{4}-\mathrm{FA}_{2}\right)($ Figure 2), was synthesised and loaded with L-BSO. Folate targeting is aimed towards therapeutic applications in ovarian clear cell carcinoma. 


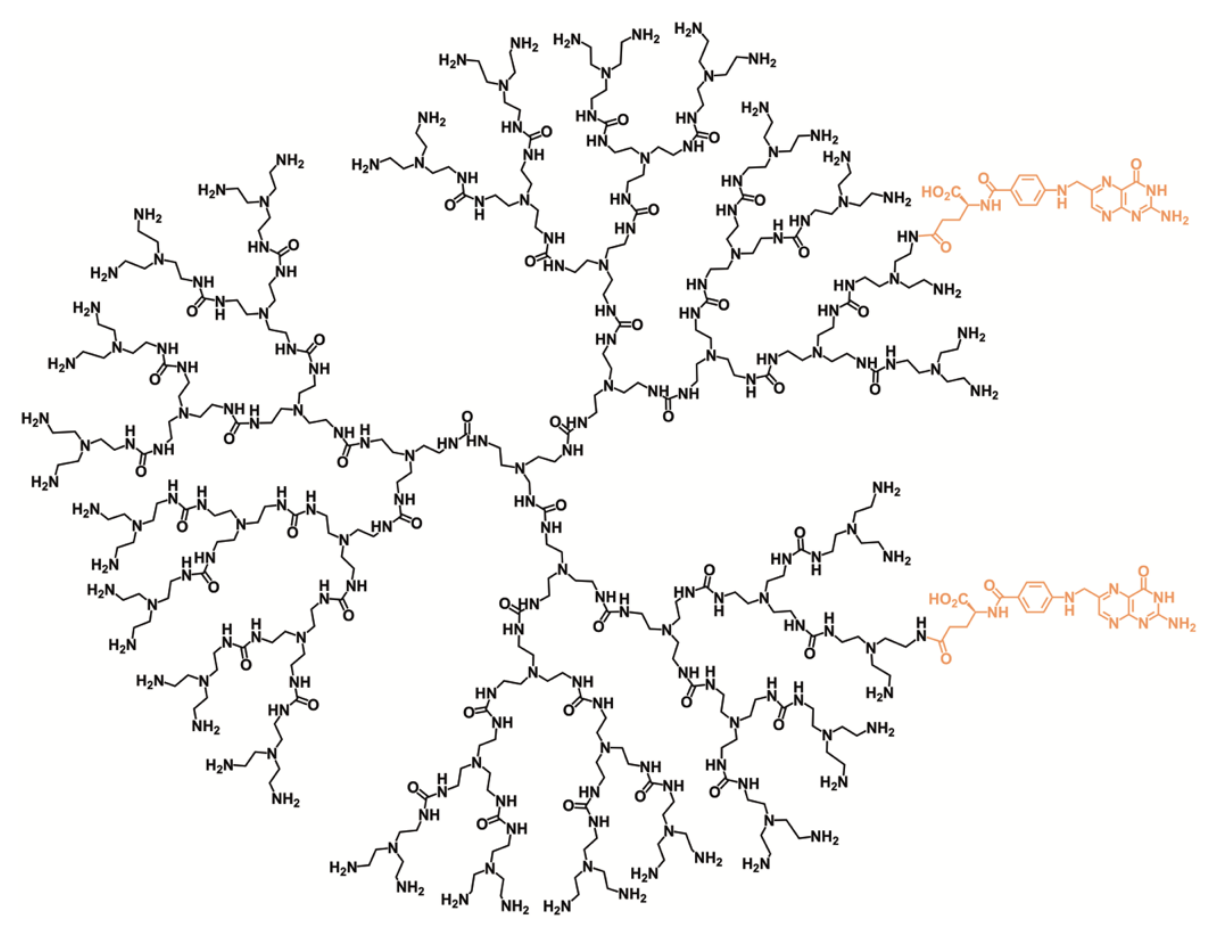

Figure 2. Chemical structure of the L-Buthionine sulfoximine (L-BSO) nanocarrier, generation four polyurea dendrimer targeted with folic acid $\left(\mathrm{PURE}_{\mathrm{G} 4}-\mathrm{FA}_{2}\right)$.

Figure 3 shows the L-BSO release profile from a L-BSO@PURE $\mathrm{G}_{4}-\mathrm{FA}_{2}$ nanoformulation at $\mathrm{pH} 7.4$. The release was followed for $24 \mathrm{~h}$ and the results indicate a burst release in the first hours, as expected in this type of delivery system $[16,17]$. After $1 \mathrm{~h}$, around $60 \%$ of the loaded drug was released to the medium, reaching a plateau after $3 \mathrm{~h}$. After $24 \mathrm{~h}, 90 \%$ of L-BSO was released, meaning that only a residual amount of $\mathrm{L}-\mathrm{BSO}$ was trapped inside the $\mathrm{PURE}_{\mathrm{G} 4}-\mathrm{FA}_{2}$ dendrimer during this period of time. The quantification of $\mathrm{BSO}$ released from the $\mathrm{PURE}_{\mathrm{G} 4}-\mathrm{FA}_{2}$ dendrimer was determined using a calibration curve, obtained from an assay under the same experimental conditions (see Figure S1 in Supporting Information). In more acidic media, a faster release is expected.

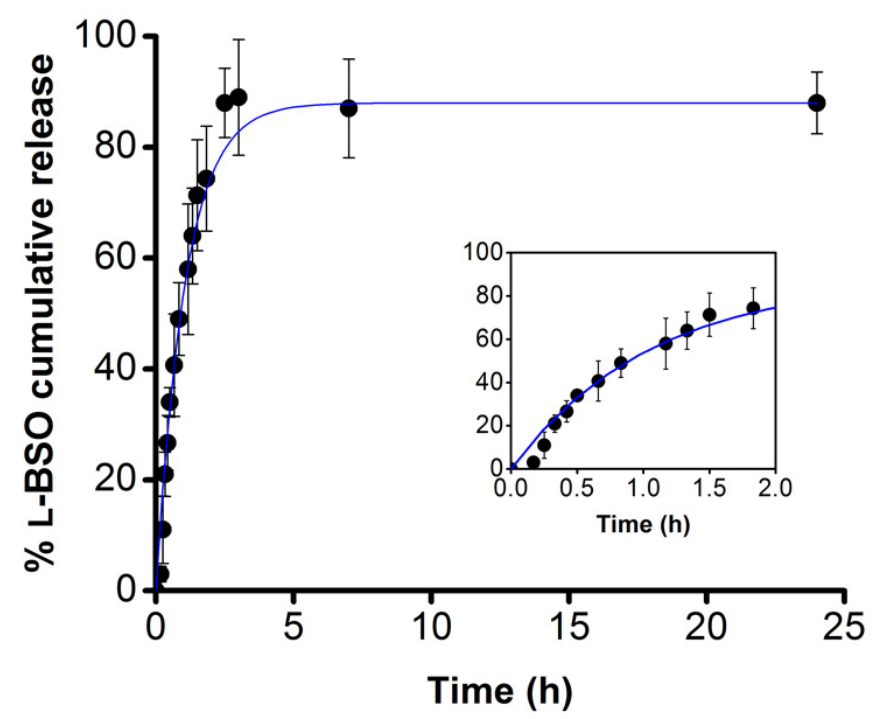

Figure 3. In vitro release profile of $\mathrm{L}$-buthionine- $(R, S)$-sulfoximine (L-BSO) encapsulated in a PURE $\mathrm{G}_{4}-\mathrm{FA}_{2}$ dendrimer (L-BSO@PURE $\mathrm{G}_{4}-\mathrm{FA}_{2}$ ) nanoformulation at $\mathrm{pH}$ 7.4. The inset shows L-BSO cumulative release in the first two hours. 


\subsection{L-BSO Detection and Quantification}

As stated before, the detection and quantification of BSO is problematic due to its very low molar absorptivity and absorption wavelength $(<200 \mathrm{~nm})$. To overcome this issue, we developed a new detection protocol using catechol as the derivatizing agent (Scheme 1).

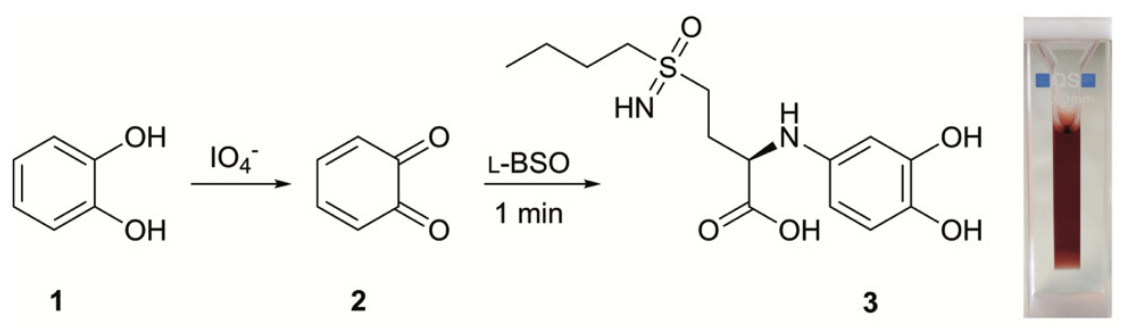

Scheme 1. L-BSO chemical derivatization. $o$-Quinone (2) is generated in situ by catechol (1) oxidation, which reacts with L-BSO to give a coloured intermediate (3).

It is known from literature that ortho phenols (e.g., catechol) react with sodium periodate, a strong oxidizing agent, to give the corresponding o-quinones [18]. The reaction is fast and the formed o-quinones are highly reactive coloured intermediates (absorption bands ca. $390 \mathrm{~nm}$ ), which easily undergo nucleophilic attack [19]. Therefore, we investigated this reaction in the presence of L-BSO in order to evaluate its applicability in a detection and quantification protocol. Since we found (data not shown) that the derivatization reaction is time dependent, thus affecting the absorbance intensity, all the triplicate data points were rigorously collected at the same time $(60 \mathrm{~s})$ using a chronometer. In this derivatization reaction, a colour change from yellow (o-quinone) to red (L-BSO derivative, $503 \mathrm{~nm}$ ) was observed.

In order to clarify the derivatization mechanism, the reaction was followed by ${ }^{1} \mathrm{H}$ NMR (Figure 4).

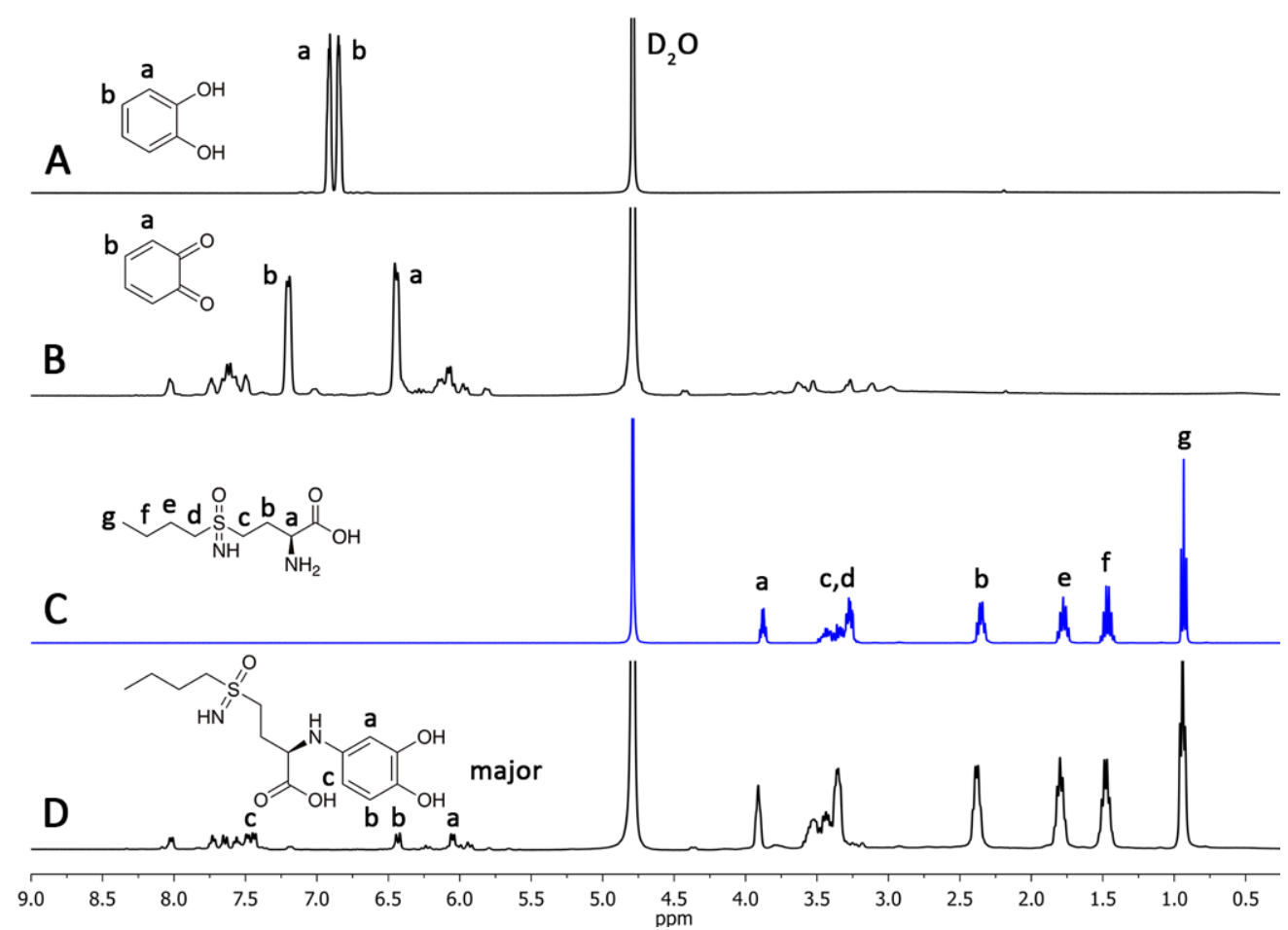

Figure 4. ${ }^{1} \mathrm{H}$ NMR spectra of the L-BSO derivatization reaction followed by NMR. Comparative spectrum of (A) catechol, (B) o-quinone, (C) L-BSO, and (D) L-BSO derivative (3). NMR spectra recorded in $\mathrm{D}_{2} \mathrm{O}$. 
In this experiment, sodium periodate was added to a NMR tube containing a solution of catechol in $\mathrm{D}_{2} \mathrm{O}$ (Figure $4 \mathrm{~A}$ ). The formation of the corresponding o-quinone is visualised by a colour change to yellow (Figure $4 \mathrm{~B}$ ). Then, a solution of $\mathrm{BSO}$ in $\mathrm{D}_{2} \mathrm{O}$ was added and spectra were recorded at intervals of $10 \mathrm{~min}$ until no more changes in the spectra were observed (total time $50 \mathrm{~min}$ ) (Figure 4D). The spectra show the formation of the Michael adduct, as expected. The ${ }^{13}$ C-NMR spectrum (see Figure S2 in Supporting Information) was recorded and a downshift was observed, especially in the region 49-54 ppm. Also, the spectrum did not show any signals around 180-190 ppm [20], which corroborates the formation of the BSO derivative 3. The higher downshift was observed for the carbon at $53.2 \mathrm{ppm}$, and the carbon linked to the BSO primary amine [5]. From these data, we may conclude that the primary amine of BSO reacts with o-quinone, thus originating intermediate 3 as a major product.

This strategy is envisaged as a simple and straightforward methodology for the detection and quantification of analytes with low wavelength absorption and having a nucleophilic functional group.

\section{Materials and Methods}

\subsection{Reagents and Materials}

L-Buthionine-( $S, R)$-sulfoximine (L-BSO) ( $\geq 97 \%$ purity) was obtained from Sigma-Aldrich. All chemicals and solvents were used as received without further purification. Polyurea (PURE) dendrimer generation four $\left(\mathrm{PURE}_{\mathrm{G} 4}\right)$ was synthesized following our reported supercritical-assisted polymerization [21].

\subsection{Synthesis of PURE $E_{G 4}-F A_{2}$}

Folate-targeted polyurea dendrimer generation four (PURE $\mathrm{P}_{4}-\mathrm{FA}_{2}$, Figure 2) was prepared by reacting PURE $\mathrm{G}_{4}$ with activated folic acid succinic ester (FA-NHS) (Scheme 2).

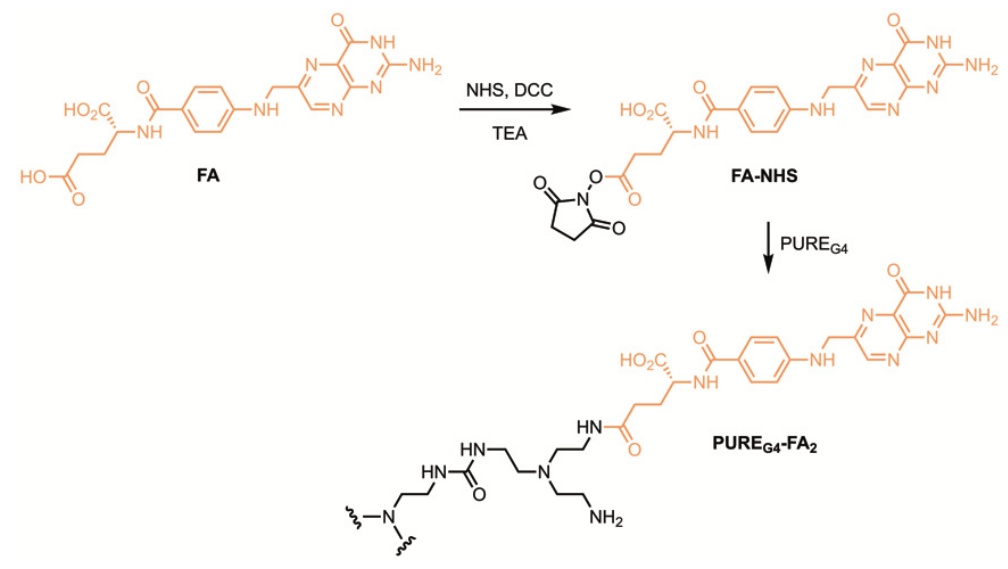

Scheme 2. Synthesis of PURE $\mathrm{G}_{4}-\mathrm{FA}_{2}$.

FA-NHS was synthesized following the literature [22]. Typically, in a round bottom flask, $250.0 \mathrm{mg}(0.566 \mathrm{mmol})$ of folic acid (FA) was dissolved in dimethylsulfoxide (DMSO) (2.75 mL). After the addition of $130.8 \mathrm{mg}(1.137 \mathrm{mmol})$ of $\mathrm{N}$-hydroxysuccinimide (NHS), $128.5 \mathrm{mg}(0.623 \mathrm{mmol})$ of dicyclocarbodiimide (DCC), and $0.15 \mathrm{~mL}$ (1.082 $\mathrm{mmol})$ of triethylamine (TEA), the reaction was stirred at room temperature (RT) overnight in the dark. The product was precipitated and washed several times with diethyl ether. After drying under vacuum, FA-NHS was obtained as a yellow powder (263.4 mg) in 86.4\% yield. ${ }^{1} \mathrm{H}$ NMR (400 MHz, DMSO-d6) $\delta(\mathrm{ppm}): 8.64(1 \mathrm{H}, \mathrm{s}), 7.63(2 \mathrm{H}, \mathrm{d}, J=8.0 \mathrm{~Hz})$, $6.64(2 \mathrm{H}, \mathrm{d}, J=8.0 \mathrm{~Hz}), 4.49(2 \mathrm{H}, \mathrm{s}), 4.28(1 \mathrm{H}, \mathrm{s}), 2.54(4 \mathrm{H}, \mathrm{s}), 2.29(1 \mathrm{H}, \mathrm{s}), 2.03(1 \mathrm{H}, \mathrm{s}), 1.93(1 \mathrm{H}, \mathrm{s})$

Next, FA-NHS was conjugated with $\mathrm{PURE}_{\mathrm{G} 4}$ (via $\mathrm{NH}_{2}$ surface groups) to obtain PURE $\mathrm{G}_{4}-\mathrm{FA}_{2}$. In a $25 \mathrm{~mL}$ bottom round flask, $100 \mathrm{mg}(0.0127 \mathrm{mmol})$ of PURE $\mathrm{G}_{4}$ was dissolved in $5.0 \mathrm{~mL}$ of DMSO. To this solution, $13.68 \mathrm{mg}(0.0254 \mathrm{mmol})$ of FA-NHS and $6.9 \mu \mathrm{L}(0.051 \mathrm{mmol})$ of TEA were added. The reaction was stirred at RT overnight in the dark. Next, TEA excess was removed on the rotary 
evaporator and diethyl ether was added. The obtained precipitate was dried under vacuum and PURE $\mathrm{G}_{4}-\mathrm{FA}_{2}$ was obtained as yellow oil in $93.9 \%$ yield. By NMR, it was found that two molecules of folic acid had been conjugated to the surface of $\mathrm{PURE}_{\mathrm{G} 4} \cdot{ }^{1} \mathrm{H}$ NMR $\left(400 \mathrm{MHz}, \mathrm{D}_{2} \mathrm{O}\right) \delta(\mathrm{ppm}): 8.64(2 \mathrm{H}$, s), $7.70(4 \mathrm{H}, \mathrm{bs}), 6.86(4 \mathrm{H}, \mathrm{d}, J=8.0 \mathrm{~Hz}), 4.61(2 \mathrm{H}, \mathrm{s}), 3.54-3.00(180 \mathrm{H}, \mathrm{m}), 2.96-2.40(462 \mathrm{H}, \mathrm{m})$.

\subsection{Encapsulation of $\mathrm{L}-B S O$ in PURE $\mathrm{G4}_{4}-F A_{2}$}

In a vial, $78.0 \mathrm{mg}(8.90 \mu \mathrm{mol})$ of $\mathrm{PURE}_{\mathrm{G} 4}-\mathrm{FA}_{2}$ was dissolved in $20 \mathrm{~mL}$ of ethanol. Then, $21.6 \mathrm{mg}$ $(0.0972 \mathrm{mmol})$ of L-BSO was added and the mixture was vigorously stirred. The encapsulation occurred at RT overnight, in the dark, for $24 \mathrm{~h}$. Afterwards, no L-BSO on suspension was observed and the product was purified by dialysis for $30 \mathrm{~min}$ (MWCO 100-500 Da). After evaporation of the solution, the product was dried under vacuum and characterized by ${ }^{1} \mathrm{H}$ NMR. The amount of L-BSO loaded into the dendrimer (BSO@PURE $\left.\mathrm{G}_{4}-\mathrm{FA}_{2}\right)$ was determined by ${ }^{1} \mathrm{H} \mathrm{NMR} .{ }^{1} \mathrm{H} \mathrm{NMR}\left(300 \mathrm{MHz}, \mathrm{D}_{2} \mathrm{O}\right) \delta$ (ppm): 8.60 (s, 2H), $7.63(\mathrm{br}, 4 \mathrm{H}), 6.78(\mathrm{br}, 4 \mathrm{H}), 3.62$ (s, 16H), 3.44-3.07 (m, 180H), 3.06-2.40 (m, 462H), $1.76(\mathrm{~m}, 32 \mathrm{H}), 1.45(\mathrm{q}, J=6.0 \mathrm{~Hz}, 30 \mathrm{H}), 0.92(\mathrm{t}, J=6.0 \mathrm{~Hz}, 48 \mathrm{H})$.

\subsection{L-BSO Release Profile}

L-BSO release studies were performed at $37^{\circ} \mathrm{C}$ in sodium phosphate buffer medium (PBS, pH 7.4). First, $6.3 \mathrm{mg}$ of L-BSO@PURE $\mathrm{G}_{4}-\mathrm{FA}_{2}$ were dispersed in $1 \mathrm{~mL}$ of medium and placed in a SnakeSkin ${ }^{\mathrm{TM}}$ dialysis membrane (MWCO $3500 \mathrm{Da}$ ). The dialysis bag was then immersed in $60 \mathrm{~mL}$ of release medium and kept in at constant temperature with stirring. Samples $(1 \mathrm{~mL})$ were periodically collected and replaced by the same volume of fresh medium. The amount of L-BSO released was determined by UV-Vis spectroscopy. The release of L-BSO from the dendrimers was obtained in triplicate.

\subsection{Quantification of BSO by UV-Vis Spectroscopy}

Using a modified protocol [18], L-BSO was derivatized in order to be detected by UV-Vis spectroscopy. L-BSO quantification was performed by adding to the samples $300 \mu \mathrm{L}$ of catechol $2.25 \mathrm{mM}$ in PBS, followed by $300 \mu \mathrm{L}$ of sodium periodate $6.75 \mathrm{mM}$ in PBS. After $60 \mathrm{sec}$, the absorption of the L-BSO derivative $(503 \mathrm{~nm})$ was measured in a PerkinElmer Lambda 25 UV-Vis Spectrometer with a slit width of $5 \mathrm{~nm}$ at a scan rate of $240 \mathrm{~nm} \mathrm{~min}{ }^{-1}$ at $25^{\circ} \mathrm{C}$. For the calibration curve, standard solutions of L-BSO were prepared in the concentration range of $0.1-150 \mu \mathrm{M}$ in PBS and processed using the same protocol. A good correlation coefficient $\left(R^{2}=0.997\right)$ was obtained (see Figure S1 in Supporting Information).

\section{Conclusions}

In summary, the detection and quantification of L-buthionine sulfoximine was performed using a polyurea dendrimer nanoformulation. The protocol is fast, accurate, simple, non-toxic, and may be applied to detect and quantify other similar drugs.

Supplementary Materials: The following are available online, Figure S1: Calibration curve of L-BSO derivatization., Figure S2: ${ }^{13} \mathrm{C}$ NMR spectra of L-BSO in situ derivatization reaction followed by NMR.

Author Contributions: Conceptualization, J.S. and V.D.B.B.; Data Curation, P.M.; Formal Analysis, P.M.; Funding Acquisition, V.D.B.B.; Investigation, P.M. and R.F.P.; Methodology, J.S. and V.D.B.B.; Supervision, J.S. and V.D.B.B.; Writing-Original Draft, P.M.; Writing-Review \& Editing, V.D.B.B.

Funding: This research was funded by Fundação para a Ciência e a Tecnologia (FC\&T, Portugal) through project PTDC/MEC-ONC/29327/2017 and by iNOVA4Health-UID/Multi/04462, a program financially supported by FC\&T through national funds and co-funded by FEDER under the PT2020 Partnership Agreement.

Conflicts of Interest: The authors declare no conflict of interest. The funders had no role in the design of the study; in the collection, analyses, or interpretation of data; in the writing of the manuscript, or in the decision to publish the results. 


\section{References}

1. Görög, S. Ultraviolet-Visible Spectrophotometry in Pharmaceutical Analysis; CRC Press: Boca Raton, FL, USA, 2018.

2. Haddad, J.J. L-Buthionine-(S,R)-sulfoximine, an irreversible inhibitor of gamma-glutamylcysteine synthetase, augments LPS-mediated pro-inflammatory cytokine biosynthesis: Evidence for the implication of an IkappaB-alpha/NF-kappaB insensitive pathway. Eur Cytokine Netw. 2001, 12, 614-624. [PubMed]

3. Griffith, O.W.; Meister, A. Potent and specific inhibition of glutathione synthesis by buthionine sulfoximine (S-n-butyl homocysteine sulfoximine). J. Biol. Chem. 1979, 254, 7558-7560. [PubMed]

4. Griffith, O.W. Mechanism of action, metabolism, and toxicity of buthionine sulfoximine and its higher homologs, potent inhibitors of glutathione synthesis. J. Biol. Chem. 1982, 257, 13704-13712. [PubMed]

5. Buglioni, L.; Bizet, V.; Bolm, C. Methionine and buthionine sulfoximines: Syntheses under mild and safe imidation/oxidation conditions. Adv. Synth. Catal. 2014, 356, 2209-2213. [CrossRef]

6. Schnelldorfer, T.; Gansauge, S.; Gansauge, F.; Schlosser, S.; Beger, H.G.; Nussler, H.K. Glutathione depletion causes cell growth inhibition and enhanced apoptosis in pancreatic cancer cells. Cancer 2000, 89, 1440-1447. [CrossRef]

7. Vanhoefer, U.; Cao, S.; Minderman, H.; Toth, K.; Skenderis, B.S.; Slovak, M.L.; Rustum, Y.M. D, L-Buthionine- $(S, R)$-sulfoximine potentiates in vivo the therapeutic efficacy of doxorubicin against multidrug resistance protein-expressing tumors. Clin. Cancer Res. 1996, 2, 1961-1968. [PubMed]

8. Lopes-Coelho, F.; Gouveia-Fernandes, S.; Gonçalves, L.G.; Nunes, C.; Faustino, I.; Silva, F.; Félix, A.; Pereira, S.A.; Serpa, J. HNF1 $\beta$ drives glutathione (GSH) synthesis underlying intrinsic carboplatin resistance of ovarian clear cell carcinoma (OCCC). Tumor Biol. 2016, 37, 4813-4829. [CrossRef] [PubMed]

9. Fan, T.; Sun, G.; Sun, X.; Zhao, L.; Zhong, R.; Peng, Y. Tumor energy metabolism and potential of 3-bromopyruvate as an inhibitor of aerobic glycolysis: Implications in tumor treatment. Cancers 2019, 11, 317. [CrossRef] [PubMed]

10. Sandor, V.; Flarakos, T.; Batist, G.; Wainer, I.W.; Lloyd, D.K. Quantitation of the diastereoisomers of L-buthionine- $(R, S)$-sulfoximine in human plasma: A validated assay by capillary electrophoresis. J. Chromatogr. B Biomed. Sci. Appl. 1995, 673, 123-131. [CrossRef]

11. Duff, R.; Murrill, E. Determination of L-buthionine- $(S, R)$-sulfoximine in plasma by high-performance liquid chromatography with o-phthalaldehyde derivatization and fluorometric detection. J. Chromatogr. 1987, 385, 275-282. [CrossRef]

12. Campbell, E.B.; Hayward, M.L.; Griffith, O.G. Analytical and preparative separation of the diastereomers of L-buthionine (SR)-sulfoximine, a potent inhibitor of glutathione biosynthesis. Anal. Biochem. 1991, 194, 268-277. [CrossRef]

13. Warburg, O.; Wind, F.; Negelein, E. The metabolism of tumors in the body. J. Gen. Physiol. 1923, 309, 97-519. [CrossRef] [PubMed]

14. Pires, R.F.; Moro, A.; Lourenço, A.; Lima, J.C.; Casimiro, T.; Bonifácio, V.D.B. Molecular weight determination by luminescent chemoenzymatics. ChemistrySelect 2016, 1, 6818-6822. [CrossRef]

15. Restani, R.B.; Conde, J.; Baptista, P.V.; Cidade, M.T.; Bragança, A.M.; Morgado, J.; Correia, I.J.; Aguiar-Ricardo, A.; Bonifácio, V.D.B. Polyurea dendrimer for efficient cytosolic siRNA delivery. RSC Adv. 2014, 4, 54872-54878. [CrossRef]

16. Restani, R.B.; Conde, J.; Pires, R.F.; Martins, P.; Fernandes, A.R.; Baptista, P.V.; Bonifácio, V.D.B.; Aguiar-Ricardo, A. POxylated polyurea dendrimers: Smart core-shell vectors with IC50 lowering capacity. Macromol. Biosci. 2015, 15, 1045-1051. [CrossRef] [PubMed]

17. Restani, R.B.; Silva, A.S.; Pires, R.F.; Cabral, R.; Correia, I.J.; Casimiro, T.; Bonifácio, V.D.B.; Aguiar-Ricardo, A. Nano-in-micro POxylated polyurea dendrimers and chitosan dry powder formulations for pulmonary delivery. Part. Part. Syst. Charact. 2016, 33, 851-858. [CrossRef]

18. Khalafi, L.; Rafiee, M.; Fathi, S. Effect of $\beta$-cyclodextrin on intra and intermolecular Michael addition of some catechol derivatives. Spectrochim. Acta A Mol. Biomol. Spectrosc. 2014, 118, 695-701. [CrossRef] [PubMed]

19. Nematollahi, D.; Rafiee, M.; Fotouhi, L. Mechanistic study of homogeneous reactions coupled with electrochemical oxidation of catechols. J. Iran Chem. Soc. 2009, 6, 448-476. [CrossRef]

20. Obermeyer, A.C.; Jarman, J.B.; Francis, M.B. N-Terminal modification of proteins with o-aminophenols. J. Am. Chem. Soc. 2014, 136, 9572-9579. [CrossRef] [PubMed] 
21. Restani, R.B.; Morgado, P.I.; Ribeiro, M.P.; Correia, I.J.; Aguiar-Ricardo, A.; Bonifácio, V.D.B. Biocompatible polyurea dendrimers with $\mathrm{pH}$-dependent fluorescence. Angew. Chem. Int. Ed. 2012, 51, 5162-5165. [CrossRef] [PubMed]

22. Yoon, K.; Harris, J.M.; Bentley, M.D.; Fang, Z.; Viegas, T. Multifunctional Forms of Polyoxazoline Copolymers and Drug Compositions Comprising the Same. U.S. Patent 8,501,899, 23 January 2012. 